\title{
Em busca dos contos de fadas na contemporaneidade
}

\author{
Paulo Ailton Ferreira da Rosa Juniorl (D) \\ Vania Grim Thies" (D)
}

\begin{abstract}
RESUMO
Este artigo tem o objetivo de explicitar como alguns elementos das narrativas literárias conhecidas como contos de fadas continuam circulando entre os jovens leitores. Para tal, a metodologia utilizada foi baseada no grupo focal, no qual um conjunto de adolescentes em idade escolar foi reunido para debater o tema "contos de fadas" a partir de suas impressões pessoais e conhecimentos prévios. Foi possível verificar que elementos dos contos de fadas continuam presentes em séries, filmes e livros populares entre eles, mas que há distanciamento dos textos clássicos do gênero. Assim, o trabalho traz contribuições para a Educação ao elucidar o estado da permanência do gênero contos de fadas nas práticas correntes de leitura e consumo cultural do grupo de jovens leitores pesquisado.
\end{abstract}

PALAVRAS-CHAVE

contos de fadas; jovens leitores; literatura e mídias. 


\section{LOOKING FOR CONTEMPORARY FAIRY TALES}

\section{ABSTRACT}

This paper aims to explain how elements of literary narratives known as fairy tales are still disseminated among young readers. To do so, it applied the focus group method, in which school-age teenagers gathered to discuss the topic "fairy tales" based on their personal impressions and previous knowledge. It was possible to verify that elements of fairy tales are still present in television shows, movies, and popular books. However, there is some distance from the classic texts of traditional fairy tales. Therefore, this paper contributes to the field of Education by elucidating the permanent status of fairy tales in common reading and cultural consumption practices of the group of young readers surveyed.

KEYWORDS

fairy tales; young readers; literature and media.

\section{BUSCANDO CUENTOS DE HADAS EN LA CONTEMPORANEIDAD}

\section{RESUMEN}

Este artículo tuve el objetivo de exponer cómo algunos elementos de las narrativas literarias conocidas como cuentos de hadas siguen circulando entre los lectores jóvenes. Para tanto, la metodología utilizada está basada en el grupo focal, en el que se reunió un grupo de adolescentes en edad escolar para discutir el tema "cuentos de hadas" desde sus impresiones personales y conocimientos previos. Fue posible comprobar que elementos de los cuentos de hadas siguen presentes en series televisivas, películas y libros populares entre ellos; sin embargo, hay un distanciamiento de los textos clásicos del género. Por consiguiente, este trabajo contribuye con la Educación al aclarar el estado de permanencia del género cuentos de hadas en las prácticas actuales de lectura y de consumo cultural del grupo de lectores jóvenes estudiado.

PALABRAS CLAVE

cuentos de hadas; lectores jóvenes; literatura y medios de comunicación. 


\section{INTRODUÇÃO}

Considerada de menor importância pelos críticos até o início da década de 1990, o que convencionamos chamar de literatura infantojuvenil vem recebendo cada vez mais atenção de pesquisadores, marcada por um momento em que, como ressalta Hunt (2010,p. 27), a teoria e a crítica passaram a se preocupar com aspectos que vão desde e além do texto, como a reação pessoal do leitor ao que está lendo e o pano de fundo político de sua produção. É nessa conjuntura que estudos que envolvem os textos literários produzidos para a infância e a juventude (ou os que acabaram por cair no gosto delas, ou que a elas foram relegados - sempre uma problemática definição) vêm ressaltando a questão da perenidade dos contos de fadas e da sua enorme receptividade através das gerações.

Assim, este trabalho é resultado de uma pesquisa de mestrado em Educação, cujo objetivo geral foi problematizar o que jovens leitores têm a dizer sobre contos de fadas, a fim de compreender o fenômeno da permanência dessas histórias na contemporaneidade. Para este artigo, seguinte a uma reconstituição histórica e conceitual do gênero que ajudará a elucidar o material com que trabalhamos, o foco é explicitar como alguns dos elementos desses contos ainda estão presentes e circulam atualmente entre o grupo pesquisado: os jovens.

Os dados que aqui serão tratados tiveram origem em interações de um grupo de discussão, técnica inspirada no grupo focal, a partir de Gatti (2012), metodologia que reúne um conjunto de pessoas e pesquisadores para discutir e comentar sobre um tema que é o objeto da pesquisa em questão. Trata-se, portanto, do resultado de uma pesquisa qualitativa, pois, segundo Minayo (2003, p. 22), esta "aprofunda-se no mundo dos significados das ações e relações humanas". Procuramos, a partir dessa perspectiva, destacar as diversas opiniões e compreensões dos participantes do estudo, a fim de pensar o tema dos contos de fadas apoiados em autores como Zipes (1999, 2000, 2006), Bettelheim (2014), Darnton (1988), Coelho (2000), dentre outros, entendendo que, como ressaltam Silva e Rocha (2008, p. 14), "hoje, estudar os contos de fadas é perceber as demandas de ficção do homem contemporâneo e suas articulações com os novos modelos civilizatórios”.

Em um momento em que as áreas tendem a fechar-se cada vez mais em si, esta pesquisa traz contribuições importantes para a educação graças ao seu caráter interdisciplinar com os estudos literários. A discussão proposta traz aspectos de uma área para o âmbito da outra, a fim de potencializar a compreensão de ambas acerca do tema. Os contos de fadas, bem como o acervo em geral da literatura infantojuvenil, estão intimamente ligados ao trabalho com a literatura enquanto disciplina desde os seus primórdios, e o conhecimento aprofundado dessa matéria fortalece seu manejo pelos profissionais da Educação. Para além, buscamos, também, contribuir para o estado do conhecimento sobre a história da leitura desse gênero literário em especial, que já completa três séculos.

Primeiramente, o artigo apresenta a delimitação teórica e histórica do gênero conto de fadas, e, posteriormente, discute os contos de fadas na atualidade a partir da concepção de um grupo de jovens, detendo-se em três aspectos principais: as características que eles reconhecem como definidoras do gênero, os contos que a 
pesquisa revelou como mais populares no grupo, juntamente de suas diferentes versões, e, ainda, a presença dos elementos desses contos em outras produções da literatura e das mídias surgidas nos séculos XX e XXI.

\section{CONTOS DE FADAS: UMA DELIMITAÇÃO TEÓRICA E HISTÓRICA DO GÊNERO}

Se pedirmos a palavra a um grupo de pessoas, e dissermos, então, "Era uma vez", todos ali imediatamente entenderão que estão prestes a ouvir uma história bem conhecida. Pode ser Chapeuzinho Vermelho, A Bela Adormecida, Branca de Neve, ou outra qualquer. Tradicionalmente, essa forma léxica que nos faz esperar por algo familiar vem introduzindo histórias há muitos e muitos séculos, e está posta também em textos modernos e contemporâneos como maneira de aludir a um determinado tipo de narrativa que aprendemos a chamar de "contos de fadas", ainda que, se formos questionados mais a fundo, não tenhamos tanta clareza do que o gênero especificamente designa. Zipes (2006) afirma que essas histórias, narradas como as conhecemos hoje, são resultado de um complicado processo de adaptação feito da tradição oral popular para a escrita, entre séculos XVI e XVII, e que, basicamente, foram sendo readaptadas até os nossos tempos contemporâneos, sempre absorvendo elementos das culturas em que estiveram inseridas.

De modo geral, afirma Merege (2010), os estudiosos das diversas áreas que se interessam pelos contos de fadas concordam que as origens primeiras dessas narrativas estão nas histórias nascidas na oralidade pré-cristã e que foram contadas pelas primeiras tribos humanas, ao redor de suas fogueiras, onde relatos do cotidiano confundiam-se com fabulações e ritos de passagem, em uma complexa dinâmica religiosa e social. Algumas delas viriam a se mesclar ao substrato mitológico europeu na gênese dos contos de fadas propriamente ditos, contendo "elementos provenientes daquele imaginário ancestral, povoado de seres mágicos, animais fantásticos, feiticeiros, deuses e gênios, além de um herói (ou heroína) enviado numa jornada que é ao mesmo tempo a busca de um objetivo e do autoconhecimento" (Merege, 2010 p. 8), tendo, por isso, um caráter fabular, por assim dizer, maravilhoso.

O conceito de "maravilhoso" aponta, essencialmente, para Todorov (2012). Muito confundido com o elemento fantástico, que se trata da "vacilação experimentada por um ser que não conhece mais que as leis naturais, frente a um acontecimento aparentemente sobrenatural" (Todorov, 2012, p. 16), e que, grosso modo, está presente nos romances fantásticos como Peter Pan e Alice no País das Maravilhas, os quais nasceram de um interesse moderno na magia ancestral dos contos de fadas, e que são frequentemente confundidos com esse gênero (Nikolajeva, 2003). O maravilhoso, garante Todorov, aponta na direção contrária. Assim, ele expressa que: "costuma-se a relacionar o gênero do maravilhoso com o do conto de fadas; em realidade, o conto de fadas não é mais que uma das variedades do maravilhoso e os acontecimentos sobrenaturais não provocam nele surpresa alguma" (Todorov, 2012, p. 30). Nas histórias de cunho maravilhoso, a título de exemplificação, podem ser percebidos elementos que, aos olhos das personagens, do leitor implícito e mesmo 
do narrador, tão característico, não provocam qualquer espanto: seja o sono que dura cem anos, o lobo que fala, ou mesmo os dons mágicos das fadas.

Provavelmente, essas criaturas da imaginação popular, as fadas, figuram no termo "contos de fadas" pela crença que as antigas culturas europeias tinham de que a palavra das fadas é capaz de encantar os mortais de forma irrecuperável (Silva e Rocha, 2008), algo que os contos têm feito, através dos séculos, com as suas próprias palavras, que, assim, assemelham-se então à das fadas. Cagneti (2013) assinala que, etimologicamente, o termo "conto de fadas" aponta para a França do século XVII, onde nasceu a expressão conte de fée, "por meio do registro escrito dos contos de tradição oral que ganham força com contadores como Charles Perrault" (Cagneti, 2013, p. 63).

Assim, ainda que alguns autores creditem os italianos Straparola e Basile como os primeiros a trazer essas histórias de cunho popular para a literatura formal escrita, costuma-se postular Charles Perrault como o primeiro cânone dos contos de fadas. A primeira edição de sua obra intitulada Histórias ou contos do tempo passado com moralidades - em tradução livre -, ou Contos de Mamãe Gansa — como ficou conhecido graças à inscrição da gravura que ilustrava a capa -, data de 11 de janeiro de 1697 e reuniu, em sua versão final, onze contos: A Bela Adormecida no bosque, Chapeuzinho Vermelho, Barba Azul, Mestre Gato ou O Gato de Botas, As fadas, Borralheira ou A chinelinha de cristal, Riqueti de topete, Pequeno Polegar, Griseldis, Pele de asno e Desejos ridiculos. Merege (2010, p. 52) nos diz que foi especificamente com essa publicação de Perrault que essas narrativas se fixaram e se perpetuaram, "constituindo-se como peça fundadora de um corpus literário que, embora tenha sido tratado como um gênero menor, conservou-se ao longo de 300 anos".

Jolles (1976, p. 191) aponta que "depois da publicação dos Contos de Perrault, narrativas do mesmo gênero inundaram a França e o resto da Europa”, o que o nos leva à Alemanha, berço daqueles que talvez sejam a maior autoridade quando pensamos em compiladores dessas histórias: os Irmãos Grimm. O feito de Jacob e Wilhelm Grimm, intelectuais do século XIX, foi transformar sua pesquisa, que buscava registrar e preservar na escrita a essência dos povos germânicos presente apenas na oralidade, desenvolvida a partir da recolha escrita dos relatos orais de sabedoria popular, em uma antologia de contos que ganhou o gosto do público. Intitulada Kinder-und Hausmärchen - traduzida para o inglês como Nursery and Household Tales, ou, em português, Contos maravilhosos infantis e domésticos (Grimm e Grimm, 2012) - a publicação, que teve como fonte não apenas contadoras de histórias, mas também documentos escritos, surgiu como um compêndio de estudo acadêmico em dois volumes, lançados nos anos de 1812 e 1815, mas foi ganhando tamanha popularidade devido ao seu conteúdo que, ao final das sete reedições em 1857, havia se transformado em um livro de histórias para as crianças e a família.

Nessas reedições, revisões sistemáticas foram efetuadas pelos Grimm. Elas foram impulsionadas pela intenção de higienizar os contos, pois o ideário cristão que se consolidava à época levantou grande polêmica com relação ao conteúdo de muitas das narrativas de Kinder-und Hausmärchen, consideradas demasiadamente cruéis. Por isso, a partir de 1819, "os Grimm, na segunda edição da coletânea, retiraram episódios de demasiada violência ou maldade, principalmente aqueles que 
eram praticados contra crianças" (Coelho, 2012, p. 29). Zipes (2006) conta que foi Wilhelm quem começou com as revisões, limpando as narrativas do teor considerado impróprio. Tatar (2003, p. 38, tradução nossa) completa: "o que pareceu muito cruel ou ofensivo para os ouvidos infantis foi eliminado. Grosserias, frases pouco elegantes foram polidas e refinadas", mesmo que algumas coisas tenham passado.

Zipes (2006, p. 84, tradução nossa) afirma que: "ainda que seja difícil fazer uma estimativa precisa, os contos de Grimm (junto de certas versões de Perrault) são provavelmente os mais reimpressos e mais conhecidos no mundo, servindo como referência para todo tipo de produção cultural". São atribuídos aos Grimm títulos como Branca de Neve, João e Maria, Rapunzel e A princesa e o sapo, por exemplo. Em seu compêndio, há também uma versão de $A$ gata borralheira e um texto chamado Jardim de verão e jardim de inverno, que divide o substrato de Eros e Psique com o qual a Dama de Villeneuve desenvolveu A Bela e a Fera. Sobre isso, Darnton (1988, p. 74) explica:

Alguns poucos contos franceses quase não se diferenciam de seus equivalentes na coleção de Grimm. Mas, apesar das exceções e das complicações, as diferenças entre as duas tradições enquadram-se em padrões consistentes. Os narradores camponeses abordavam os mesmos temas e lhes faziam modificações características, os franceses de uma maneira, os alemães de outra. Enquanto os contos franceses tendem a ser realistas, grosseiros, libidinosos e cômicos, os alemães partem para o sobrenatural, o poético, o exótico e o violento.

Com efeito, devemos aos Grimm "o fato de muitos dos contos de fadas que eles compilaram, editaram e publicaram não terem sido esquecidos até hoje, mesmo depois de 200 anos da publicação da primeira edição dos Contos da infância e do lar" (Betterman, 2013, p. 40). O mundo sem essas histórias, com certeza, seria outro:

Em inúmeros poemas, dramas e romances surgiriam partes vazias. Possivelmente, eles não seriam nem mesmo escritos. Não saberíamos o que é "bom" e o que é "mal", não haveria "maldade", mas também não haveria "compaixão" como no conto "As moedas-estrelas" ("Die Sterntaler"). Teríamos pouca noção do sentido de "bonito" e "feio", não conheceríamos "azar", mas também não conheceríamos "sorte" como experiência "João sortudo" ("Hans im Glück"). Não haveria "medo", mas também não haveria "coragem". Não aconteceriam mais milagres. Estaríamos sozinhos nesta terra, sem os seres fantásticos e misteriosos dos céus, da água e dos reinos subterrâneos. (Betterman, 2013, p. 37)

E, possivelmente, não teríamos também o nome de Hans Christian Andersen, tal qual o temos hoje, vinculado ao maior prêmio da literatura infantojuvenil, lembrado como o pai dos contos de fadas modernos. Em geral, nos diz Mylius (2006, p. 166, tradução nossa), "a fama de Andersen é baseada em dez ou doze histórias concebidas como contos de fadas e, para o seu infortúnio, muitas vezes misturadas com as de Grimm". Mas, na historiografia literária, o papel de Andersen é bem maior. 
Diferente de seus predecessores alemães e francês, o dinamarquês Andersen era, antes de tudo, um escritor, e o seu objetivo, longe de qualquer estudo ou interesse político, era criar trabalhos literários. De fato, ele clamava para si a autoria dos contos de fadas que escreveu, tendo os concebido de uma mistura de material folclórico com imaginações próprias. Cagneti (2013, p. 59) conta que Andersen "provinha de uma família humilde, tendo passado dificuldades que não apenas relatou em sua biografia (1832) como deixou transparecer em vários de seus mais de 150 contos, nos quais, muitas vezes, coisas ruins acontecem com seres bons e puros". É o caso, por exemplo, de A pequena vendedora de fósforos, A pequena sereia, e tantos outros.

Torna-se interessante ressaltar que, mesmo renegando fortemente essas produções como seu principal acervo, foi "nos contos de fadas, mais do que em qualquer outro [gênero], que ele chegou perto do seu antigo sonho de expressar algo que nunca havia sido expressado antes, criando o que se aproximaria de uma nova concepção de literatura" (Mylius, 2006, p. 170, tradução nossa). Assim, Zipes (2000, p. 14, tradução nossa) nos fala que "há várias maneiras pelas quais Andersen pode ser nomeado o criador do gênero moderno dos contos de fadas", pois transgrediu diversas das regras do gênero, ao mesmo tempo conseguindo mantê-lo dentro de seus limites. Além da presença do tradicional elemento maravilhoso em suas histórias, no âmbito da narrativa, ele construía uma ambientação moderna, e, no âmbito da linguagem, expressava inconfundível individualidade, sempre carregando seus textos com um tom de ironia; um bom exemplo é $A$ roupa nova do imperador.

O que o trabalho de Andersen nos lega, principalmente, é a conclusão de que ele lidou tão bem com essas narrativas que, ainda que seus contos de fadas pareçam tão genuínos quanto aqueles recolhidos da tradição oral, "eles se colocam em um contexto literário diferente, imitando os contos de fadas e os gestos da literatura infantil, mas, por trás, vão muito além dos dois” (Mylius, 2006, p. 172, tradução nossa). Cagneti (2013) nos diz que tal contexto inspirou diversos outros autores a enveredar pelo estilo, podendo destacar, por exemplo, a Condessa de Ségur, com seus Nouveaux contes de fées, e Carlo Collodi, com Pinóquio. É no mesmo período, também, que começa a nascer o romance moderno (Watt, 2010) e as suas narrativas fantásticas.

É possível que, muito por influência dos filmes de animação de Walt Disney, diversas das obras romanescas com características fantásticas produzidas a partir de então, como Peter Pan, Alice no País das Maravilhas ou $O$ mágico de $\mathrm{Oz}$, sejam facilmente confundidas no saber popular com os contos de fadas, dos quais diferem tremendamente, apesar de figurarem na filmografia do estúdio junto a diversos títulos de contos de fadas. A respeito desse problema conceitual, Nikolajeva (2003, p. 138, tradução nossa) escreve que "o conceito de conto de fadas e fantasia é frequentemente usado de modo indiscriminado para se referir a qualquer coisa que não seja uma prosa rigorosamente realista", por isso a confusão. Entrementes, como característica primordial que distingue o conto de fadas das obras fantásticas, aponta-se que os primeiros são histórias com raízes nas sociedades antigas e no pensamento mágico, herdeiros imediatos dos mitos, enquanto as narrativas da segunda matiz são um fenômeno dos tempos modernos, nascido da curiosidade da arte literária romântica sobre a tradição folclórica dos contos de fadas (Zipes, 2000). 
Zipes (1999) discorre ainda que a marca que Walt Disney - enquanto importante cineasta do século XX — imprimiu na tradição dos contos de fadas influenciou a forma como os conhecemos atualmente, de tal modo que, inclusive, o seu próprio nome confunde-se hoje com o gênero em si, e suas adaptações para histórias como Branca de Neve, A Bela Adormecida e Cinderela, por exemplo, mudaram profundamente tanto a forma quanto o significado anteriores destes contos.

É possível encontrar, hoje, publicações que narram as versões de Disney para os contos de fadas, bem como miscigenações delas com os textos canônicos de Perrault, Grimm e Andersen, em incontáveis edições que, por vezes, nem creditam a esses nomes a organização dos contos. Caracterizam-se, assim, como um reconto completamente livre da história em questão, versões que são colagens de diversas fontes impossíveis de rastrear. Não obstante, escritores contemporâneos também vêm se apropriando dessas histórias seculares e reescrevendo-as com outros contornos, às vezes em tons de paródia, às vezes em tons de mistério ou horror, talvez inspirados pelo cinema e pela televisão, cujos formatos audiovisuais produzidos já há algum tempo revisitam os contos de fadas, criando novas variações e combinações, em narrativas em que personagens de histórias diferentes se encontram e se confundem, às vezes, como uma nova e única história.

É a partir desse terreno que esta pesquisa se dedicou, então, a rastrear, para perseguir os contos de fadas na contemporaneidade. A próxima seção discute a relação dos contos de fadas na atualidade a partir da concepção de um grupo de jovens.

\section{OS JOVENS, OS CONTOS DE FADAS E A CONTEMPORANEIDADE}

As pesquisas com grupos focais privilegiam a seleção dos participantes segundo alguns critérios, conforme o problema em estudo. Ao definir que buscaríamos em um grupo de adolescentes as respostas para nossas questões, fugimos de um público comumente tido como alvo, e, potencialmente, mais interessado em contos de fadas - as crianças - para rumar por uma via que, à primeira vista, poderia ser incerta, mas que acreditávamos poder nos revelar muito mais sobre o estado do assunto, visto que, como explicitado anteriormente, a temática se embrenha fortemente com os artefatos culturais do entretenimento dos quais os sujeitos da faixa etária são principal público: de best-sellers a blockbusters.

Convencionamos chamar "grupo de discussão", e não "grupo focal", a metodologia utilizada nesta coleta de dados com os adolescentes, pois, ao longo do seu desenvolvimento, acabamos nos afastando de dinâmicas de interação mais reguladoras sugeridas por autores de apoio e que surgem como mecanismos mais usuais nessa técnica, como o roteiro de perguntas pré-estruturado, para outras atividades mais lúdicas. Como, ainda assim, mantivemos a essência da técnica original, uma vez que ela "envolve algum tipo de atividade coletiva" (Gatti, 2012, p. 7), postulamos que o "grupo de discussão", utilizado no desenvolvimento da pesquisa com o grupo de jovens, inspira-se no "grupo focal", e, por isso, muitas vezes, voltamos a ele.

Assim, a partir, principalmente, de um chamamento em uma rede social, mas também por meio de contatos com colegas de pesquisa, foram selecionados sete jovens, 
três meninas e quatro meninos, adolescentes entre 13 e 17 anos $^{1}$, oriundos de diferentes contextos, escolas da rede municipal, estadual, particular e federal, para integrar esse grupo pesquisado. Como Gatti (2012, p. 9) postula que esse tipo de pesquisa "tem por objetivo captar, a partir das trocas realizadas no grupo, conceitos, sentimentos, atitudes, crenças, experiências e reações", para a análise aqui proposta foi feita uma seleção de declarações oferecidas pelos adolescentes durante os nove encontros do grupo, que foram registrados em áudio, e, posteriormente, transcritos. Porém, no intuito de preservar as identidades dos participantes, eles estão identificados de J1 a J7 ao lado de suas contribuições.

O percurso desta análise começa buscando determinar que características o grupo entendeu como definidoras de uma narrativa de conto de fadas. Mensuramos quais dessas histórias são as mais populares entre eles e em quais versões, buscando, por último, compreender como elementos dos contos de fadas ainda se fazem presentes nas narrativas com que esses jovens se relacionam contemporaneamente.

Assim, quando levamos em consideração Sale (1977, p. 372) ao dizer que o termo "conto de fadas" é apenas uma convenção para nomear certo tipo de história que todos identificamos instintivamente de acordo com o que incluem ou excluem, de fato, verificamos que o grupo, ao longo dos encontros, não demonstrou dificuldades para selecionar narrativas que considerassem contos de fadas. Os participantes não titubearam em oferecer exemplos, nem discordaram entre si quanto aos títulos citados, muito menos duvidaram dessas escolhas, pelo menos até serem indagados mais profundamente sobre o que as histórias citadas possuíam em comum, como transcrito a seguir:

Ah, eu tô pensando em contos de fadas como historinhas que tem magia $e$ final feliz, tô certo? (J3)

A constatação de que os contos de fadas "têm magia" já havia sido repetida muitas vezes antes disso:

Eu acho que ele [o conto de fadas] é bem fora da realidade da gente, tipo numa realidade mágica. (J2)

[conto de fadas] Tem magia. (J6)

[conto de fadas] Tem uma certa magia. (J3)

[conto de fadas] Tem bastante magia. (J7)

Eles [os contos de fadas] sempre tem um pouquinho de mágica. (J4)

E essa característica, a "mágica", foi explicada como um estado em que "existem coisas que não tem, sabe? Tipo, uma princesa dormir cem anos, um animal falar,

1 O uso das gravações e transcrições para a pesquisa, bem como a divulgação dos dados obtidos, foi autorizado pelos pesquisados e seus responsáveis em termos de consentimento, que também passaram por aprovação de comitê de ética na Plataforma Brasil. 
essas coisas [...]" (J3). No domínio teórico, esse caráter "mágico" é compreendido pelo elemento maravilhoso, como explorado por Coelho (2000, p. 172):

No início dos tempos, o maravilhoso foi a fonte misteriosa e privilegiada de onde nasceu a literatura. Desse maravilhoso nasceram personagens que possuem poderes sobrenaturais; deslocam-se contrariando as leis da gravidade; sofrem metamorfoses contínuas; defrontam-se com as forças do Bem e do Mal, personificadas; sofrem profecias que se cumprem; são beneficiadas com milagres; assistem a fenômenos que desafiam as leis da lógica, etc.

Portanto, o grupo concordou que o que o conto de fadas faz, essencialmente, é narrar acontecimentos que se distanciam dos limites do que é aceito usualmente como "real", sendo histórias de caráter extraordinário, fabular, mais do domínio da imaginação do que do materialismo, e que "sempre acabem bem" (J1), afinal, "todo mundo tem aquela ideia de que conto de fadas é perfeito e vai ter final feliz" (J2).

Para Bettelheim (2014, p. 54), o final feliz é a característica dos contos de fadas que reassegura a esperança humana da resolução de todos os conflitos da vida, pois, nas suas palavras, "a história de fadas é sempre otimista, não importa o quão terrivelmente sérias possam ser algumas características desta última”. Assim, no conto de fadas, "tudo dá certo no final, pras crianças comę̧arem a acreditar nisso" (J7).

Entretanto, se investirmos em um exame mais minucioso nas narrativas publicadas por Perrault, Grimm e Andersen, é facilmente verificável que os finais felizes não são tão comuns assim. A ideia do final feliz como elemento característico dos contos de fadas difundiu-se amplamente apenas no século XX, em razão das adaptações cinematográficas de Walt Disney para essas histórias, visto que, como nos diz Parma (2009, p. 515), "é próprio do discurso da Disney que o fim de seus filmes seja feliz, sintetizado pela frase 'e viveram felizes para sempre', para que ele agrade às crianças que lhe assistem”, visando à conquista do público infantil, aos quais os filmes eram direcionados.

Não por acaso, ao compor uma lista com as dez narrativas mais citadas como contos de fadas pelo grupo durante a pesquisa, oito já ganharam versões animadas pelos estúdios Disney. Elas estão organizadas, da mais citada a menos citada, na Tabela 1.

Com exceção de Chapeuzinho Vermelho e João e Maria, as demais narrativas foram adaptadas para o cinema de animação produzido pela marca Walt Disney nos anos de 1937 (Branca de Neve), 1950 (Cinderela), 1951 (Alice no País das Maravilhas), 1953 (Peter Pan), 1959 (A Bela Adormecida), 1989 (A pequena sereia), 1991 (A Bela e a Fera) e 2010 (Rapunzel, adaptada com o título Enrolados) ${ }^{2}$. Pela força dessas produções, é comum pensar que contos de fadas e Disney são, praticamente, sinônimos, como alguns momentos dos encontros os jovens demonstraram:

Eu acho que se não tem filme da Disney, não é conto de fadas. (J5)

2 Dados retirados do site IMDb, também conhecido como Internet Movie Database. 
Tabela 1 - As dez narrativas indicadas pelo grupo como contos de fadas.

\begin{tabular}{c|c}
\hline 1 & Branca de Neve \\
\hline 2 & Peter Pan \\
\hline 3 & A Pequena Sereia \\
\hline 4 & Chapeuzinho Vermelho \\
\hline 5 & Cinderela \\
\hline 6 & Alice no País das Maravilhas \\
\hline 7 & Rapunzel \\
\hline 8 & A Bela e a Fera \\
\hline 9 & A Bela Adormecida \\
\hline 10 & João e Maria \\
\hline
\end{tabular}

Fonte: elaboração dos autores.

eu tava pensando nos filmezinhos da Disney que tem princesas. (J3)

quando eu penso em contos de fadas eu sempre lembro das histórias da Disney. (J6)

Entrementes, nem toda narrativa Disney é uma adaptação de algum conto de fadas, bem como nem todo conto de fadas tem uma adaptação Disney. Os casos de Peter Pan e Alice no País das Maravilhas, como demonstrados no tópico de revisão histórico-teórica do gênero, comprovam a primeira afirmação, e a ausência de Chapeuzinho Vermelho e João e Maria na cinebiografia de Disney comprovam a segunda. A seguir, exploraremos individualmente cada conto de fadas citado, buscando compreender o que permaneceu sobre eles entre o grupo pesquisado.

Branca de Neve foi frequentemente citado pelos participantes do grupo como Branca de Neve e os Sete Anões, título que, segundo Zipes (1999), é uma marca registrada da Disney e alude à adaptação do conto pelo estúdio. Refere-se, portanto, a uma versão diferente da história como a encontrada no texto literário clássico de Grimm e Grimm (2012).

Assim, Tatar (2003, p. 233) afirma que essa versão para o cinema, de 1937, de Branca de Neve e os Sete Anôes, "tornou-se uma força cultural tão dominante que virtualmente apagou todas as outras versões da história, inclusive a dos Grimm". Selecionamos como declaração mais sintomática desse prevalecimento de uma versão sobre a outra o momento em que os participantes falam sobre os Sete Anões:

Essa é a parte mais importante! Como era o nome deles? (J4)

Tem o Zangado, o Atchim [...]. (J3)

O Mestre! (J7)

O Dunga, o Manhoso. (J4) 
Afora o fato de não haver um anão chamado Manhoso na versão de Disney, essa individualização dos anões é uma característica forte e principal da versão do cinema dessa história, uma vez que o texto de Grimm e Grimm (2012) não nomeia os anões, em acordo com uma característica muito peculiar dos contos de fadas: a de que os personagens são arquétipos completamente planos, desprovidos de individualidade. A atenção aos anões é, portanto, um elemento importante apenas para a animação.

Apequena sereia (também traduzido no Brasil como A sereiazinha) é o único conto de Andersen na lista composta a partir dos relatos do grupo, que parece ter conhecimento das duas versões: a de Andersen (2011) e a de Disney. A primeira fica muito clara quando os adolescentes lembram do final trágico que essa história possui:

[...] e aí o principe casa com outra e ela tenta matar ele, só que dai ela não consegue, dai ela se joga na água e, tipo, morre, teoricamente. Não, desculpa, ou ela matava o principe, ou ela sumiria. E ai ela tenta matar o principe e não consegue e se joga na água. (J3)

Sobre isso, Corso e Corso (2006, p. 146) comentam que "menos feliz que o desenho musical homônimo dos Estúdios Disney (1989), a Pequena sereia original só enfrenta dissabores do começo ao fim”. Já a segunda versão conhecida no grupo está expressa no fato de os participantes atribuírem nomes próprios aos personagens, o que só existe no filme de animação:

É... o que a Ariel mais queria, a Úrsula disse que daria se a Ariel desse a voz em troca, mas depois ela foi lá e fez de tudo para atrapalhar a Ariel [...]. (J4)

Meu personagem favorito é o Linguado. (J6)

No caso de Chapeuzinho Vermelho, Bettelheim (2014, p. 235) comenta que "uma menina encantadora e 'inocente' engolida por um lobo é uma imagem que deixa na mente uma marca indelével”. Não foi à toa, então, que o grupo concentrou-se, majoritariamente, nesse motivo central: "quando eu era pequena me assustava bastante a parte da boca grande pra me comer melhor" (J6). Possivelmente por não possuir uma versão Disney que apagasse essa influência, marcas de várias versões apareceram durante as interações:

A própria história da Chapeuzinho Vermelho que a gente conhece, minha tia contou que era uma releitura, que, na verdade, no final, na história principal, o Lobo comeu todo mundo [...]. (J6)

Também já li sobre isso... O lobo... ele... dá a carne e o sangue da vovó pra Chapeuzinho tomar e comer e depois mata ela [...]. (J7)

O que as transcrições aqui fazem supor é que não houve, por parte dos componentes do grupo, um contato com versões dos textos originais de Perrault (2018), apenas leituras sobre eles. Isso se deu, provavelmente, porque as versões correntes de Chapeuzinho Vermelho eliminam todas as partes em que violências acontecem 
explicitamente, com exceção do fato da protagonista e a avó serem devoradas, o que tem aguçado a publicação de artigos (alguns bastante errôneos) em diversas revistas e sites de internet sobre essas origens "censuradas" dos contos de fadas. Para além, sobre esse conto em especial, um filme também foi lembrado: "Tem aquele filme, A garota da capa vermelha, que o lobo mau é o namorado dela" (J1).

Quanto a Cinderela, o conto é definido por Bettelheim (2014, p. 333) como uma história "a respeito das agonias da rivalidade fraterna, de desejos se tornando realidade, de humildes sendo exaltados, do verdadeiro mérito sendo reconhecido mesmo quando oculto sob farrapos, da virtude recompensada e da maldade castigada". Tanto Perrault quanto Grimm têm versões dessa narrativa em seus compêndios, cujos elementos misturam-se a características da adaptação de Disney nas percepções do grupo. Elas ficam claras em afirmações como, por exemplo: "Ela [Cinderela] tem sempre a ajuda dos animaizinhos, né, pra limpar a casa" (J5), fato que não existe em nenhum dos textos literários de Grimm ou Perrault, caracterizando-se como um elemento de Disney. Entretanto, quando lembram que "aparece a fada e dai dá o vestido pra ela ir ao baile e conhecer o principe" (J1), o grupo alude tanto à Disney quanto a um elemento oriundo da versão de Perrault, a fada; e quando dizem que "as irmãs cortaram os pés pra caber no sapatinho de cristal' (J6), não referem-se nem a um nem a outro, mas aos Grimm, que têm a versão mais cruel das três.

Sobre Rapunzel, Corso e Corso (2006, p. 64) ressaltam que "a marca registrada desse conto é o exílio na torre sem portas", a primeira coisa que o grupo demonstrou saber acerca da história: "Ela cresceu trancada numa torre, com medo do mundo, coitada" (J4). Esse conto constitui um caso semelhante ao de Branca de Neve dentro do grupo, visto que também foi majoritariamente mencionado a partir do título da adaptação de Disney, Enrolados: "Eu não sei a história da Rapunzel, só a dos Enrolados” (J3). Ainda que estabeleçam uma relação direta entre Enrolados e Rapunzel, certamente pelo nome da protagonista ter sido mantido no filme como uma alusão direta ao conto de fadas, o grupo não demonstrou ter lido o conto dos Grimm:

Não sei se isso tem relação com o conto... mas no Enrolados ela tem o cabelo mágico que se escovar e cantar a pessoa fica jovem. (J6)

E tem o José Bezerra, que é um ladrão e não um príncipe, como geralmente tem nessas histórias. Não sei se é assim no conto. (J5)

Uma análise primeira considerou que as percepções do grupo sobre $A$ Bela e a Fera conduziam pela contramão das oferecidas sobre Rapunzel, trazendo muitos elementos dos textos literários. Entretanto, quando os participantes começaram a evocar personagens não existentes nesses textos - "Eu adoro o Lumière?" (J6), em relação a um candelabro falante presente na animação; "[...] e tem o Gaston que é bonito, mas ruim" (J2) - ficou claro que a versão de Disney era mais forte e os aspectos que aludiam à versão literária só se apresentavam por que o texto-fonte do filme é, exatamente, aquele considerado clássico sob o título de $A$ Bela e a Fera: o de Jeanne-Marie Leprince de Beaumont, publicado em 1756, como corroborado por 
Griswold (2004). Essa versão, ainda que seja possível inferir em Jardim de inverno $e$ de verão, de Grimm, um enredo muito semelhante, é considerada uma releitura da versão de Madame de Villeneuve, publicada em 1740.

Quando o assunto foi $A$ Bela Adormecida, ainda que o grupo se referisse constantemente ao conto com o título popularizado por Grimm, demonstraram, mais uma vez, ter como versão mais marcante a produzida pelos estúdios Disney. Entretanto, desta vez, não a animação:

Ah, na Bela Adormecida tem Malévola, eu lembro pela Malévola. (J7)

A Malévola amaldiçoou ela no nascimento dizendo que ela picaria o dedo no fuso de uma roca e morreria, mas dai as fadinhas mudaram a magia pra que ela só dormisse um sono profundo. (J6)

É, e na verdade a Malévola não era má, só tinha sido magoada pelo pai da bela adormecida. (J1)

Essas falas referem-se ao live-action, ou seja, à versão com "atores de carne e osso", lançada em 2014, sob o nome da vilã popularizada pela animação de 1959.

Sobre a última narrativa mais citada, João e Maria, Corso e Corso (2006, p. 45) dizem que "a maior parte deste conto gira ao redor do comer: começa com a fome em casa, o banquete na casa da bruxa (onde se comem até as paredes), o terror de serem devorados e conclui com um belo assado de bruxa”. O que os participantes do grupo demonstraram foi exatamente o fato do tema ser extremamente marcante:

Os pais deixaram eles na floresta pra não morrer de fome em casa, mas deram só um pãozinho pra eles não morrerem de fome na floresta, o que não faz o menor sentido. (J1)

Eles acharam a casa da bruxa, que era feita de doces, e como eles estavam com fome porque o João botou fora todo o pão, eles começaram a comer a casa, dai veio a bruxa e disse que ia acolher eles, mas era pra comer eles. (J3)

Todo mundo sente muita fome nesse conto. (J6)

$\mathrm{Na}$ falta de uma versão de Disney, como no caso de Chapeuzinho Vermelho, eles lembraram de outra adaptação: "eu conheço a versão em que eles mataram ela [a bruxa] e viraram caçadores de bruxas" (J7), referindo-se ao filme João e Maria: caçadores de bruxas, lançado em 2013.

A forte influência de elementos de narrativas fílmicas, em animação ou em live-action, nas percepções do grupo sobre os contos de fadas corrobora algo que Menna (2017, p. 13) já averigua quando postula que "com efeito, há na contemporaneidade um franco processo de movência de narrativas, de translação de eventos e de sistemas de pensamento, de renovação tecnológica que dinamiza o território do fantástico". Ou seja, as narrativas dessa matiz, o fantástico, da qual os contos de fadas fazem parte sob a especificidade do maravilhoso, não mais conseguem ser compreendidas em sua completude sem que se estabeleçam relações com os outros textos que delas se desprendem ou das quais elas próprias se desprendem. Tendo isso 
como evidência, a autora propõe refletir sobre o fantástico e seus arredores, sendo um deles o âmbito dos contos de fadas, pensando que, atualmente, quando lidamos com essas ficções, estamos nos ocupando de um fenômeno que extrapola a literatura oral e escrita e torna-se intermidiático, em que as histórias são construídas em um movimento que vai dos livros para as telas, ou vice-versa. Portanto, a autora conclui:

As pesquisas no universo das produções literárias e culturais para crianças e jovens têm nos motivado a transbordar o âmbito da literatura e a investigar diversos campos narrativos, cujas manifestações artísticas se expressam em formas outras de linguagens e a perscrutar os diálogos que essas linguagens estabelecem com a verbal. (Menna, 2017, p. 14)

É possível que, por isso, antes dos livros, os contos de fadas tenham aparecido nas declarações do grupo fortemente relacionados ao cinema e à TV. Foram recorrentes menções a outros filmes, além dos presentes nas transcrições aqui apresentadas, tais como Branca de Neve e o caçador e João, o caçador de gigantes - que revisita o conto de João e o pé de feijão, por exemplo. Esses filmes adaptam as histórias a que aludem para "versões sombrias", como denominadas pelo próprio grupo. Foi frequente a menção à versão do seriado mexicano Chaves para Branca de Neve e às séries americanas Grimm e Once Upon a Time, que subvertem diversos desses clássicos infantis, a última mencionada em absolutamente todos os encontros. Assim, Hunt (2010, p. 281) caracteriza a literatura infantojuvenil atual como hipertextual, pois, segundo ele, o que anteriormente se consideravam itens externos ou alheios à narrativa principal, como as adaptações, tornaram-se parte dela. Em outras palavras, os novos textos produzidos para além e a partir do texto "clássico" da literatura estão incorporando-se a ele como parte integrante do universo de fruição da história. Nos contos de fadas, quem começou isso foi Disney.

Zipes (1999, p. 332) afirma que se crianças ou adultos pensarem em contos de fadas hoje em dia, sejam quais forem, "suas primeiras e talvez mais duradouras impressões desses contos e outros terão emanado de um filme, livro ou artefato da Disney":

Eu, quando eu penso em conto de fadas, eu penso em Disney. Eu acho que não tem como não pensar na Disney primeiro, nos filmezinhos deles. E em livro infantil que diz "conto de fadas" na capa... tem muitos destes da Disney também, com imagens das princesas dos filmes na capa. (J6)

Eu tinha desses livrinhos... no comę̧o meus pais que liam, depois eu fui aprendendo a ler e lia sozinho. Tinha os contos de fadas das princesas, mas também tinha d'O Rei Leão, do Mogli [...]. (J3)

A direta correspondência dos contos de fadas à Disney feita pelo grupo levou à decisão de tentar mensurá-la a partir de uma contagem de indicadores no corpus. Como demonstra a Tabela 2, as palavras "filme" e "Disney" foram usadas mais vezes, no grupo, para se referir aos contos de fadas, do que as palavras "livro" e "livrinho", que apontam diretamente para o suporte dessas histórias na literatura. 
Tabela 2 - Indicadores e a recorrência do seu uso pelo grupo, em relação ao gênero conto de fadas ou a algum conto de fadas específico.

\begin{tabular}{c|c}
\hline Termo & Recorrência \\
\hline Disney & 44 vezes \\
\hline Filme & 35 vezes \\
\hline Livro(s) e livrinho(s) & 33 vezes \\
\hline
\end{tabular}

Fonte: elaboração dos autores.

Ah, os livrinhos... ninguém me contava histórias, mas eu tinha uns livrinhos daqueles de contos de fadas pra ler. Tinha mais figuras que palavras, às vezes era só uma linha por página, mas igual eu tinha preguiça de ler. (J3)

Essa fala provavelmente referindo-se a edições que adaptam os textos de Perrault, Grimm e Andersen para leitores que ainda estão adentrando a aventura da leitura. Sobre isso, Colomer (2017, p. 43) atenta para o fato de que, na versão dos Grimm, por exemplo, "apenas o primeiro parágrafo de Branca de Neve já é muito maior que o texto completo de uma grande parte dos livros para leitores iniciantes". Assim, os textos canônicos dos contos de fadas têm sido editados em publicações que dificilmente caem nas mãos das crianças, a quem geralmente se oferecem essas versões encurtadas. Existem duas formas de olhar para esse fenômeno: de um lado, entendendo a importância desses materiais de leitura como propagadores e mantenedores da tradição dos contos de fadas e como um primeiro intercurso válido da criança na literatura escrita; e, de outro, preocupando-se com o quanto essas versões acabam substituindo por completo a leitura dos textos clássicos e empobrecem a experiência do leitor que já está apto para avançar, mas não se depara com o texto clássico.

Quando eu cresci, eu não queria mais aqueles livrinhos, eu rasguei todos e botei fora porque eram coisa de criança. Eu queria ler outras coisas. (J5)

Ainda que soe como uma ruptura brusca, essas "outras coisas" que eles confessaram ler não se distanciaram tanto assim dos contos de fadas, como, por exemplo, a série Harry Potter, citada várias vezes. Não é à toa que histórias como a do menino bruxo são rotuladas pela mídia como "contos de fadas modernos", mas, como alertam Corso e Corso (2006, p. 182), trata-se de um engano: "elas não são a mesma coisa que os seus precursores, os contos de fadas folclóricos. Inclusive porque a modernidade apresenta questões diferentes daquelas de nossos antepassados".

Colomer $(2017$, p. 214) fala dessa gama de histórias atuais que flertam com os elementos imaginativos comuns aos dos contos de fadas como uma "nova forma de ficção fantástica que pode dividir-se entre a reformulação dos usos tradicionais do folclore, a criação de um tipo de 'fantasia moderna' e um novo gênero de 'alta fantasia' ou 'fantasia épica juvenil'". Na mesma direção, foram citadas, também, leituras de Crepuisculo, Os instrumentos mortais, As crônicas de Nárnia, O Hobbit, O senhor dos anéis e Percy Jackson, exemplos desse filão que vem compondo um acervo não apenas literário, mas também audiovisual, e formando massas de ávidos leitores, no que a autora chama de uma modernização da 
literatura infantojuvenil, que passa a incluir "formas e recursos provenientes da inter-relação entre a literatura e os meios audiovisuais"(Colomer, 2017, p. 219).

\section{CONSIDERAÇÕES FINAIS}

Compreender quais elementos dos contos de fadas permanecem circulando entre os jovens leitores na contemporaneidade significou averiguar de que forma os sujeitos histórica e culturalmente situados no tempo corrente se relacionam com essas narrativas enquanto leitores e espectadores delas. A temática se embrenha fortemente com os artefatos culturais do entretenimento dos quais os sujeitos da faixa etária que compuseram o grupo são principal público: de best-sellers a blockbusters.

Assim, por 300 anos, desde a publicação de Charles Perrault que inaugurou o gênero dos contos de fadas no que hoje concebemos como literatura infantojuvenil, temos lido, ouvido, contado e assistido a essas histórias nas mais diversas versões: desde as clássicas, que vêm ganhando traduções diretas nos últimos anos, mas que se fazem muito presentes no repertório oral, contendo um pouco do mundo cruel experimentado pelos camponeses europeus do início da idade moderna, passando pelas mais tematicamente higienizadas e linguisticamente simplificadas pelo trabalho editorial, às quais os estudiosos criticam fortemente por expurgarem a riqueza simbológica original, até as televisivas e cinematográficas, que tendem a incorporar elementos da atualidade em suas tramas.

Tendo em vista todo o explanado até aqui, torna-se possível afirmar, então, que os contos de fadas enquanto matéria literária perderam espaço para suas variantes no cinema e na televisão. O que o grupo pesquisado indica sobre essas histórias é que tem se estabelecido um distanciamento cada vez maior com relação às suas versões literárias clássicas, que pouco ou não circulam entre eles para além de um "ouvi dizer que". Assim, Rapunzel, em vez de aludir a um texto literário de Grimm, faz principalmente lembrar o filme Enrolados da Disney, por exemplo.

É possível, também, concluir que o interesse pela pelas histórias de imaginação, pelas narrativas que rompem com a ideia do impossível, do improvável, do que concebemos ordinariamente como real, que nos arrancam de uma existência mundana para uma aventura na qual a magia rege as leis do mundo não se findou na infância. A sedução que os contos de fadas provocavam nesses jovens quando crianças segue muito viva nos interesses de leitura contemporâneos, como demonstrado pelo grupo ao apresentar os livros que escolhem ler atualmente - romances que apresentam traços do mesmo universo fantástico em que os contos de fadas são possíveis.

\section{REFERÊNCIAS}

ANDERSEN, H. C. Contos de Hans Christian Andersen traduzidos do dinamarquês. Trad. Silva Duarte. São Paulo: Paulinas, 2011.

BEAUMONT, M.; VILLENEUVE, M. A Bela e a Fera: a versão clássica e a surpreendente versão original. Trad. André Telles. Rio de Janeiro: Zahar, 2016.

BETTELHEIM, B. A psicanálise dos contos de fadas. Trad. Arlene Caetano. São Paulo: Paz e Terra, 2014. 
BETTERMAN, R. Os contos de fadas desconhecidos dos Irmãos Grimm. In: MOURA, M.; CAMBEIRO, D. (orgs.). Magias, encantamentos e metamorfoses: fabulações modernas e suas expressões no imaginário contemporâneo. Rio de Janeiro: De Letras, 2013. p. 33-56.

CAGNETI, S. S. Leituras em contraponto: novos jeitos de ler. São Paulo: Paulinas, 2013. COELHO, N. N. Literatura infantil: teoria - análise - didática. 1. ed. São Paulo: Moderna, 2000.

COELHO, N. N. O conto de fadas: símbolo - mitos - arquétipos. 4. ed. São Paulo: Paulinas, 2012.

COLOMER, T. Introdução à literatura infantil e juvenil atual. São Paulo: Global, 2017. CORSO, D. L.; CORSO, M. Fadas no divã: psicanálise nas histórias infantis. Porto Alegre: Artmed, 2006.

DARNTON, R. O grande massacre dos gatos e outros episódios da história cultural francesa. Trad. Sonia Coutinho. Rio de Janeiro: Graal, 1988.

GATTI, B. A. Grupo focal na pesquisa em ciências sociais e humanas. Brasília: Liber Livros, 2012.

GRIMM, J.; GRIMM, W. Contos maravilhosos infantis e domésticos. São Paulo: Cosac Naify, 2012.

GRISWOLD, J. The meanings of "Beauty and the Beast": a handbook. Toronto: Broadview Press, 2004.

HUNT, P. Crítica, teoria e literatura infantil. São Paulo: Cosac Naify, 2010.

JOLLES, A. Formas simples. São Paulo: Cultrix, 1976.

MENNA, M. Z. O fantástico, seus arredores e figurações do insólito. In: CUNHA, M. Z.; MENNA, L. (orgs.). Fantástico e seus arredores: figurações do insólito. São Paulo: FFLCH, 2017. p. 13-15.

MEREGE, A. L. O conto de fadas: origens, história e permanência no mundo moderno. São Paulo: Claridade, 2010.

MINAYO,M.C.S.(org.).Pesquisa social: teoria, método e criatividade.Petrópolis: Vozes, 2003.

MYLIUS, J. "Our time is the time of the fairy tale": Hans Christian Andersen between traditional craft and literary modernism. Marvels \& Tales, Detroit, v. 20, n. 2, p. 166-178, 2006. Disponível em: https://doi.org/10.1353/mat.2007.0014. Acesso em: 21 set. 2021. NIKOLAJEVA, M. Fairy tale and fantasy: from archaic to postmodern. Marvels \& Tales, Detroit, v. 17, n. 1, p. 138-156, 2003. Disponível em: https://doi.org/10.1353/ mat.2003.0014. Acesso em: 21 set. 2021.

PARMA, A. F. A homogeneização de gêneros literários nos filmes de Walt Disney. Revista Língua, Literatura e Ensino, Campinas, v. 4, p. 506-516, 2009. Disponível em: https://revistas.iel.unicamp.br/index.php/lle/article/view/743. Acesso em: 21 set. 2021. PERRAULT, C. Contos da Mamãe Gansa ou histórias do tempo antigo. Trad. Leonardo Fróes. São Paulo: SESI, 2018.

SALE, R. Fairy tales. The Hudson Review, New York, v. 30, n. 3, p. 372-394, 1977. Disponível em: https://doi.org/10.2307/3850269. Acesso em: 21 set. 2021. 
SILVA, G.; ROCHA, L. F. M. Quem conta um conto de fadas: uma introdução ao mundo da fantasia. Rio de Janeiro: Confraria do Vento, 2008.

TATAR, M. The hard facts of the Grimm's fairy tales. New Jersey: Princeton University Press, 2003.

TODOROV, T. Introdução à literatura fantástica. Trad. Maria Clara Correa Castello. São Paulo: Perspectiva, 2012.

WATT, I. A ascensão do romance: estudos sobre Defoe, Richardson e Fielding. São Paulo: Companhia das Letras, 2010.

ZIPES, J. Break the Disney spell. In: TATAR, M. (ed.). The classic fairy tales: texts, criticism. New York: WW Norton \& Company, 1999. p. 333-352.

ZIPES, J. (ed.). The Oxford companion to fairy tales. New York: Oxford University Press, 2000.

ZIPES, J. Why fairy tales stick: the evolution and relevance of a genre. New York: Routledge, 2006.

\section{SOBRE OS AUTORES}

Paulo Ailton Ferreira da Rosa Junior é doutorando em letras pela Universidade Federal de Santa Maria (UFSM).

E-mail: juuniorferreira@yahoo.com.br

Vania Grim Thies é doutora em educação pela Universidade Federal de Pelotas (UFPel). Professora da mesma instituição.

E-mail:vaniagrim@gmail.com

Conflitos de interesse: Os autores declaram que não possuem nenhum interesse comercial ou associativo que represente conflito de interesses em relação ao manuscrito.

Financiamento: Conselho Nacional de Desenvolvimento Científico e Tecnológico (CNPq).

Contribuições dos autores: Administração do projeto, Análise Formal: Rosa Junior, P. A. F.; Thies, V. G. Investigação, Curadoria de Dados, Conceituação, Escrita - Primeira Redação: Rosa Junior, P. A. F. Metodologia, Supervisão, Escrita - Revisão e Edição: Thies, V. G.

Recebido em 28 de setembro de 2020

Aprovado em 22 de março de 2021 